\title{
Clause-final negation and the Jespersen cycle in Logoori
}

\author{
Marjorie Pak ${ }^{*}$
}

\begin{abstract}
This paper looks at Jespersen-cycle effects in Logoori (Bantu, western Kenya), where a clause-final adverb daave (NEG2) reinforces or replaces the older negative prefixes $s i$ - and $t a$ - (NEG1). In main-clause indicatives, NEG1 is nearly obsolete (('si)-a-sooma daave 's/he's not reading'), while in subjunctives NEG1 remains obligatory ( $u$-*(ta)-sooma daave 'don't read'). Recognizing that this pattern cannot be fully attributed to the phonological weakness of NEG1 (cf. Jespersen 1917:4ff), I provide a supplementary grammar-competition analysis, in which the availability of a high-attaching, semantically negative daave in main clauses leads to the rapid erosion of NEG1 si-.
\end{abstract}

Keywords. negation; Jespersen cycle; grammar competition; Bantu; Luyia

1. Introduction. Logoori (Bantu) has several negation markers, including the prefixes $s i$ - and $t a$ and the clause-final particle daave. These negators are not freely interchangeable, though; rather, their distribution is largely determined by clause type. As shown in (1)-(3), daave (alone) negates main-clause indicatives; ta- and daave obligatorily co-occur in negative subjunctives; and ta(alone) negates relative clauses. Affirmative counterparts to each example are given on the right.

(1) Main-clause indicative:

ndori isiimba mugoroova daave

1SG.saw lion yesterday NEG

'I didn't see a lion yesterday.'

(2) Subjunctive:

u-ta-sooma kitabu daave

2SG-NEG-read book NEG

' $\{$ You shouldn't / Don't $\}$ read the book.'

(3)

Relative clause:

ndaanyora kitabu [kya Mary yaa-ta-sooma] $\quad c f$. ndaanyora kitabu kya Mary yaasooma

1sG.found book REL Mary 3SG.PST-NEG-read

'I found the book [that Mary didn't read].'

This pattern presents an interesting compositionality puzzle: How can daave and ta- each contribute negative semantics in (1) and (3), rsp., without inducing a double-negation reading in (2)? Why doesn't (2) end up meaning NEG1 + read + NEG2 = 'Don't not read'?

Note that the ta-...daave structure in (2) is not unusual in itself: bipartite negation (or embracing negation) is a well-known feature of traditional French (ne...pas) and many other languages (see e.g. Bell 2004, Devos \& van der Auwera 2013). In fact, the presence of bipartite negation is often taken as a sign that the language is undergoing a change in progress-viz., a JESPERSEN CYCLE (JC). The JC is illustrated with French in (4):

\footnotetext{
* Many thanks to Michael Diercks, John Gluckman, Michael Marlo, Lelia Glass and my audiences at Georgia Tech and the University of Georgia for helpful comments and discussion. I am also grateful to the Emory Program in Linguistics, students in our fall 2018 field methods class, my collaborator and co-instructor Yun Kim, and our wonderful Logoori language consultant. Author: Marjorie Pak, Emory University (mgpak@emory.edu).
} 
Jespersen cycle in French (Old French to modern colloquial French)

$\begin{array}{ccccc}\text { stage } 1 & \text { stage } 2 & \text { stage } 3 & \text { stage } 4 & \text { stage } 5 \\ \text { je ne sais } & \rightarrow \text { je ne sais (pas) } & \rightarrow & \text { je ne sais pas } \\ \text { NEG1 } & \text { NEG1 + (NEG2) } & \text { NEG1 + } \text { NEG2 }_{(\text {ne) sais pas }} & \text { (NEG1) + NEG2 } & \text { je sais pas } \\ \text { NEG2 }\end{array}$

In $§ 2-\S 3$ I show that Logoori is also undergoing a JC: the negative prefixes si- and $t a$ - from Proto-Bantu are being reinforced (stage 3 ) or replaced (stage 5) by incoming daave. But the question stands: Why does Logoori have the distinct, split pattern in (1)-(3)? More generally, what factors are at work in driving the JC, and how much do they vary cross-linguistically?

In $\S 4$ I argue for a grammar-competition analysis of the pattern in (1)-(3), where the availability of a high-attaching, semantically negative daave in main clauses leads to the rapid erosion of NEG1 $\mathrm{si}$-. This account is distinct from-but compatible with - accounts that attribute JC effects to the phonological weakening of NEG1. In \$5 I show that cognates of si-, ta- and daave have a very different distribution in Logoori's closest (Luyia) relatives - underscoring the point that there is more than one kind of JC (Biberauer 2009, van der Auwere 2009).

2. Phonological weakness as a Jespersen cycle trigger. Negative morphemes are crosslinguistically susceptible to reanalysis, as famously noted by Jespersen 1917:4:

(5) 'The history of negative expressions in various languages makes us witness the following curious fluctuation: the original negative adverb is first weakened, then found insufficient and therefore strengthened, generally through some additional word, and this in turn may be felt as the negative proper...'

Jespersen (1917:4-6) goes on to identify two potential triggers for this kind of change, both involving the phonological weakening of preverbal NEG1. First, he points out that sentential NEG typically gets secondary stress when there is a contrastively-focused word in the sentence (e.g. I did nòt see JÓHN). Since contrastive focus is so frequent in discourse, NEG may over time be reanalyzed as an inherently unstressed (phonologically weak) affix or clitic. Second, Jespersen says there is a 'natural tendency... for the sake of clearness' to have NEG as early as possible in the sentence. This utterance-initial placement, however, then makes NEG susceptible to deletion by 'prosiopesis' (e.g. do you Remember him?, the Fact is....).

In both of these situations, there arises an incongruity: NEG carries a heavy semantic load but is phonologically weak (or absent). This incongruity creates pressure for a postverbal reinforcing NEG to be adopted.

The phonological weakness of NEG1 could certainly have been a factor in triggering the JC in Logoori, given that Logoori NEG1 is a monomoraic prefix. Logoori in fact inherited two prefixal negators from Proto-Bantu, 'pre-initial' si- (NEG1a) and 'post-initial' ta- (NEG1b), whose distribution is fixed by clause type (Meeussen 1967, cited in Nurse 2008:30ff,ch5). Before daave came in, Logoori probably negated clauses in much the same way as contemporary Luganda (another Lacustrine Bantu language) (6): NEGla te- (cf. si-) in main clauses and NEG1b ta- in relatives, subjunctives and/or infinitives:

(6) a. abasajja [te- ba- Ø- a- leet- a] emigugu 'The men didn't bring the bundles.'

b. abasajja a-[Ø- ba- ta- a- leet- a] migugu 'the men who didn't bring bundles'

NEG1a subject.AGR NEG1b tense root Luganda (Pak 2007) 
While Luganda has not (yet) adopted a reinforcing NEG2, many other Bantu languages have; see also Devos \& van der Auwera 2013:
a. Mbugwe
JC stage 2
siye te-kw-a-re-feen-er-a
masibitali (toko)
1PL.PRO NEG1-1PL-TNS-run-APPL-FV hospital NEG2
b. Rangi
JC stage 3
'We were not running to hospitals at all.' (Gibson \&Wilhelmsen 2015)
si a-tereka nyama ira siku tuku
NEG1 3SG-TNS-cook meat DEM day NEG2
c. Pogulo
JC stage 5
'S/he did not cook meat that day.' (Gibson \&Wilhelmsen 2015)
tu-mw-oniti ndiri
1PL-3SG.OBJ-see NEG2
'We didn't see him.' (Nurse 2008:182)

The phonological weakness of NEG1 could very well be what triggered the JC in the languages in (7) as well as Logoori. However, we have not yet explained why or how the JC continues to later stages. What exactly causes the semantic weight of negation to shift from NEG1 to NEG2? How do speakers at these intermediate stages cope with the two co-occurring NEGs? And why does NEG1 eventually becomes obsolete?

In the account I provide in $\S 4$, the answers to these questions for Logoori are largely determined by specific properties of NEG2 daave, in particular its clause-final syntax. The implication is that the forces driving the JC from stage 2 onward may vary widely from language to language; i.e., there is more than one kind of JC (Biberauer 2009, van der Auwere 2009).

Before presenting the analysis, I provide a more detailed account of the Logoori pattern.

3. The Jespersen cycle in Logoori. The following subsections describe the historical development of Logoori negation across three types of clauses: main-clause indicatives, subjunctives and relatives. We will see that the JC has advanced further in main-clause indicatives than in subjunctives, and has not advanced at all in relative clauses:

\begin{tabular}{llll} 
& main-clause indic. & subjunctive & relative \\
\hline stage 1 & si-VERB & ta-VERB & ta-VERB \\
stage 3 & si-VERB daave & ta-VERB daave & \\
stage 5 & $\varnothing$ VERB daave & & \\
\hline
\end{tabular}

Table 1. Jespersen cycle (JC) effects in Logoori, by clause type

Except where noted, the examples here were produced by a Logoori native-speaking woman in her seventies from Kakamega, Kenya, between September 2018 and December 2019. ${ }^{1}$

3.1. MAIN-CLAUSE INDICATIVES. Logoori has a NEG1a prefix from Proto-Bantu, si-, which was once the sole negative morpheme in main-clause indicatives. This older (JC stage 1) pattern is found in a 1951 Bible (Kitabu Kitakatifu) (8)a and in a traditional song (Sarvasy 2016) (8)b:

\footnotetext{
${ }^{1}$ Like many Bantu languages, Logoori (Lulogooli, Luragoli; ISO 639-3 rag; subfamily Luyia) is SVO, pro-drop, agglutinating and tonal, with an abundance of noun classes and tense-mood-aspect distinctions that are not always distinguished in my glosses. I have adopted a romanized transcription system where ny $=/ \mathrm{n} /, \mathrm{ng}$ ' $=$ prevocalic $/ \mathrm{n} /$, $\mathrm{y}=/ \mathrm{j} /, \mathrm{i}=/ \mathrm{i} /$ or $/ \mathrm{I} /, \mathrm{u}=/ \mathrm{u} /$ or $/ \mathrm{\mho} /, \mathrm{aa}=[\mathrm{a}:]$ (etc.), and tones are unmarked. Abbreviations used in glosses:

APPL applicative, CAUS causative, COP copula, FV final vowel, INF infinitive, LOC locative, OBJ object, PASS passive, PL plural, REL relative-marker, SBJ subject, SG singular, SUBJ subjunctive, TMA unspecified tense/mood/aspect. Numerals 4-9 mark noun classes.
} 

a. na si-va-li netsisoni
and NEG-3PL-COP ashamed
b. si-va-ri-nyora ku vihanwa
NEG-3PL-TMA-find LOC presents
'And they were not ashamed.' (Litanga 2:25)
'They will not find any presents.'

At some point, $s i$ - began to co-occur with clause-final daave, marking the progression from JC stage 1 to JC stage 2. Daave (daße) is likely a borrowing of the negative interjection dawe ('no') from Luo, a neighboring Nilotic language (Diercks et al., to appear). It is not known when daave started to be used for sentential negation in Luyia, but by 1947 it was sufficiently wellestablished to be described as part of the 'negative construction' in Appleby's Luyia grammar ( $\mathrm{p}$. 57). Kanyoro's 1983 grammar describes all three of the forms in (9) as grammatical in Logoori:

$$
\text { si-a-rori } \sim \text { si-a-rori daße a-rori daße ('s/he didn't see.') }
$$

(Kanyoro 1983:96ff)

In contemporary Logoori, as we saw in (1), si- is falling out of use (JC stage 4-5). Our speaker-consultant almost never used $s i$-, instead using daave alone in both elicited and narrative speech (10). This pattern is confirmed by other contemporary sources (11)-(12). ${ }^{2}$
a. v-aa-nyora ku kyo ku-rya daave 3PL-TMA-find LOC 7.REL INF-eat NEG
'They didn't find anything to eat there.' (111218-NARR2)
b. rigomya ry-aa-ry-w-a n-umwiigizi daave
5.banana 5-TMA-eat-PASS-FV by-teacher NEG
'The banana wasn't eaten by the teacher.' (111418-H09)
c. m-mu-heeza kitabu kya nd-aa-sooma muhega gwaveta daave
1SG-3SG.OBJ-give 7.book 7.REL 1SG-PAST-read year past NEG
'I'm not giving her the book that I read last year.' (111418-H27)

(11) yago ne agirigare daave

10.that COP 10.truth NEG

'That's not true.' (Gluckman \& Bowler 2016:1076)

...vakere va-arange ne zisahane zya va-aragela ko daave

2.women 2-have with 10.plate 10.REL 2-squeeze.vuchima LOC NEG

'... women didn't have plates to squeeze vuchima on.' (Sarvasy 2019:88)

Notice that daave is robustly clause-final, following the by-phrase in (10)b and the heavy objects in (10)c and (12) (see also (15)a). This is a consistent feature of daave cognates across the Luyia subfamily (Bell 2004, Diercks \& Liu in prep., Diercks et al. to appear, Kanyoro 1983:96ff).

Although NEG1 si- is absent in (10)-(12), it has not completely disappeared from Logoori. The speaker in (13), interviewed by M. Diercks, uses si- with daave:
ing'ombe si-i-ra-kw-ema maveere daave.
9.cow NEG-9-TMA-2SG-deny 6 .milk NEG
'The cow will not deny you milk.'

(cited by Sarvasy 2016)

When asked directly, our consultant accepted some sentences with si- and rejected others; I have not identified a pattern underlying her judgments (e.g. inclusion or non-inclusion of daave did not predict grammaticality). The only context where she spontaneously produced si- was in

\footnotetext{
${ }^{2}$ Kanyoro (1983:100) and Gluckman (p.c.) report two other NEG2 morphemes that can be used in place of daave in Logoori, $m b a$ and $d a$ (probably a truncation). Our consultant never used these forms in interviews, but recognized them when we showed her examples (e.g. si va-ri-nyara mba 'They will not be able to' (Sarvasy 2016:206)).

Logoori also has a periphrastic negation strategy using the verb $k u$-vura 'to miss/lack'; see $\S 3.3$ for more on this.
} 
biclausal structures (e.g. (14)), where the inclusion of si- might help to disambiguate scope (see Diercks et al. to appear: $\S 5$ for precedent for this idea). But even in these contexts, $s i$ - is not required; daave alone negates matrix 'say' in (15)a, embedded 'read' in (15)b.
Mary si-yaa-voora
[Ben yaa-sooma kitabu] daave
Mary NEG-3SG.TMA-say Ben 3SG.TMA-read book NEG
'Mary didn't say that Ben read a book.' (111418-H14)
a. John yaa-voora [Mary yaa-nywa ikahaawa] daave
John 3SG.TMA-say Mary 3SG.TMA-drink coffee NEG
'John didn't say that Mary drank coffee.'
b. Mary yaa-voora [John yaa-sooma kitabu daave]
Mary 3SG.TMA-say John 3SG.TMA-read book NEG
'Mary said that John didn't read a book.'

Example (15)b reveals another important property of daave: it can be used to negate an embedded-clause complement of 'say.' In other words, daave is not strictly a 'root phenomenon' (although it may be restricted to root and root-like clauses; see §4.4).

3.2. SubJunCTIVES. Like many Bantu languages (see Wasike 2005, Ngonyani 2013), Logoori does not have a true negative imperative. This means that negative imperatives cannot be formed by simply adding NEG to an affirmative imperative (16); instead, a negative subjunctive ('you shouldn't VERB') is used as a surrogate. In this section I describe the syntax of negative subjunctives, recognizing that some of the examples have prohibitive/imperative force.

$$
\begin{aligned}
& \text { sooma } \rightarrow \text { *si-sooma, *ta-sooma, *sooma daave } \\
& \text { 'read!' 'don't read!' }
\end{aligned}
$$

Historically, Logoori subjunctives are negated with the post-initial NEG1b prefix $t a-$ and no daave (JC stage 1). This is the form used in the 1951 Bible (Kitabu Kitakatifu: Litanga):
a. u-ta-lia ku-gwo
2SG-NEG-eat LOC-3.PRO
'Don't eat of it [tree].' $(2: 17)$
b. mu-ta-lia ku-misala gyoosi gyo mulimi
2PL-NEG-eat LOC-4.tree 4.all 4.POSS garden
'Don't eat of any trees of the garden.' (3:1)

In contemporary Logoori, as we saw in (2), NEG1b ta-obligatorily co-occurs with NEG2 daave in negative subjunctives (JC stage 3). Our consultant was very consistent here, and rejected versions of these sentences that were missing ta- or daave. Note again that daave can be used to negate a clausal complement of 'say' (20).

u-ta-mu-kar-ra mugadi daave
2SG-NEG-OBJ-cut-APPL bread NEG
'Don't cut the bread for her.' (112618-H12)
ku-ta-kuunga imburi daave
1PL-NEG-chase goat NEG
'Let's not chase the goat.' (112618:H11b)
n-da-voor-r-a Mary [a-ta-sooma kitabu daave]
1SG-TMA-say-APPL-FV Mary 3SG-NEG-read book NEG
'I told Mary not to read the book.' (062619-MP19)

The subjunctive ta-...daave pattern is confirmed in other contemporary sources (21)-(22). Leung (1991:30), however, reports that subjunctives are negated with daave only (JC stage 5) (23). I have not seen evidence for this pattern elsewhere; see end of $\S 5$ for a possible account. 
(21) u-ta-gura daave 'you shouldn't buy' / 'don't buy'

u-ta-va-koona daave 'you shouldn't help them' / 'don't help them' (Odden 2018:84-85)

(22) u-ta-reeta $\mathrm{ku}$ ing'ombe i-ve i-mbarava haango daave

2SG-NEG-bring LOC 9.cow 9-COP 9-fierce home NEG

'Don't bring home a cow that is fierce.' (Sarvasy 2016:205)

(23) ki-rum-e daave

7.OBJ-bite-SUBJ NEG2

'Don't bite it.' (Leung 1991:30)

3.3. RELATIVE CLAUSES AND CONDITIONALS. As we saw in (3), relative clauses (RCs) produced by our consultant are negated with NEGlb ta-alone; they do not include daave (JC stage 1).

(24) n-dor' isiimba [i-ta-gona]

1SG-see lion 9.REL-NEG-sleep

'I see a lion [that's not sleeping].'

(25) nd-aa-gura isuzi [ya Mary yaa-ta-deeka]

1SG-TMA-buy 9.fish 9.REL Mary 3SG.TMA-NEG-cook

'I bought the fish [that Mary didn't cook].'

(26) inyuumba [ya n-ta-ve mu] nenene

9.house 9.TMA 1SG-NEG-COP LOC big

'The house [that I'm not in] is big.' (062619-MP65)

RCs can also be negated with a periphrastic construction made up of -vura 'lack' followed by an infinitive (27). This 'lack' + INF construction is also found in other Bantu languages (Nurse 2008:183), sometimes as an alternative to prefixal negation and sometimes as the only negation strategy. Our consultant was especially inclined to use -vura + INF in RCs, but it is available in main clauses and subjunctives as well, and it appears to be the only way to negate infinitives:

mani mukari [waa-vura ko-sooma kitabu]

1SG.know woman 3SG.REL.TMA-lack INF-read book

'I know the woman [who didn't read the book].' (040319-MP08a)
ngeriza ku-vura ku-rira
cf. *ngeriza ku-ta-rira
1SG.try INF-lack INF-cry
1sG.try INF-NEGlb-laugh

'I'm trying not to cry.'

Daave was also absent from our consultant's wh-questions (29) (note that these questions have RC syntax) and conditional antecedents (30). When asked, however, she did accept some conditional antecedents with daave.

a. kindi ki kya Mary yaa-ta-gura?

7.thing 7.which 7.REL Mary 3SG.TMA-NEG1-buy

'What did Mary not buy?' / 'What is it that Mary didn't buy?'

b. waha o-ta-ve murimi?

who 3SG.REL-NEG1-COP farmer

'Who is not a farmer?' / 'Who is it that's not a farmer?'

(30)
a. ni-n-ta-ve mmuumba, Mary a-ra-rira
if-1SG-NEG1-COP LOC.house Mary 3SG-TMA-cry
'If I'm not home, Mary will cry.' 
b. Mary n-a-ta-gumira isuzi (daave), ku-ra-seka

Mary COP-3SG-NEG1-catch fish (NEG2) 1PL-TMA-laugh

'If Mary doesn't catch a fish, we will laugh.'

The fact that daave was absent from our consultant's RCs is striking, given how robust it is in her main clauses and subjunctives. I do not know how widespread this pattern is. The only other source I am aware of that specifically addresses Logoori RC negation is Kanyoro 1983and according to this source, daave is used in RCs:

$$
\begin{aligned}
& \text { wo-ta-rora da( }(\beta e) \text { 'whom you don't see' } \\
& \text { ki-ta-rora da( }(\beta e) \text { 'which does not see' }
\end{aligned}
$$

In $\S 4.3$ I propose that daave has a speaker-oriented semantics that makes it incompatible with $\mathrm{RCs}$. The proposal is necessarily underdetermined, and thus leaves room for variability: some speakers may not treat daave as speaker-oriented, and some RCs (e.g. presentative or nonrestrictive RCs) may be compatible with speaker-oriented adverbs. See also §5.

4. Analysis. We have seen that while Logoori is undergoing a $\mathrm{JC}$, the cycle has advanced further in some types of clauses than in others, resulting in a split pattern (Table 1). As pointed out in $\S 2$, the phonological weakness of NEG1 si- and ta-may explain why daave first started to be used, but cannot explain how this particular split pattern developed. More specifically:

- Q1: What exactly caused NEGla si- to decline so rapidly in main-clause indicatives?

- Q2: Why hasn't NEG1b ta- declined in parallel with $s i$-?

- Q3: Why is daave unavailable in RCs, given how robust it is elsewhere?

In the following subsections I argue that Logoori's split pattern is the result of a confluence of language-specific factors, in particular the clause-final position of daave. The analysis is laid out in hypothesized chronological steps.

4.1. STAGE 1: NEG2 STARTS OUT AS A TAG. As noted in §3.1, Luyia tawe/daave is likely a borrowing of the negative interjection dawe ('no') from neighboring Luo (Nilotic) (Diercks et al. to appear). Suppose dawe/daave first came into Logoori as a clause-external tag, separated from the main clause by an intonational boundary:

$$
\begin{array}{ll}
\text { [si-arori], [daave] } & \text { 'S/he didn't see (it), daave.' } \\
\text { [u-ta-rira], [daave] } & \text { 'Don't cry, daave.' }
\end{array}
$$

Precedent for this idea includes Schwegler 1991:209 (cited in van der Auwera 2009:12), who argues that NEG2 in Brazilian Portuguese is derived from an 'intonationally separate pragmatic particle,' and Biberauer 2009:113, who makes a similar claim for Afrikaans nie (pace Bell 2005:ch5).

$$
\begin{array}{lll}
\text { Eu não quero, não } & \rightarrow & \text { Eu não quero não } \\
\text { 1SG NEG want no } & \text { 1SG NEG want NEG } \\
\text { 'I don't want to, no!' } & \text { 'I don't want to!' }
\end{array}
$$

What semantic contribution does daave make at this early stage, apart from [+NEG]? In the absence of detailed Logoori records, we can only hypothesize based on how such tags function in other languages. One possibility is that daave had an intensifying or 'emphatic' effect, on par with English no way, not at all. Alternatively or additionally, daave may have denoted some feature of the speaker's illocutionary force ('I deny/forbid it') or epistemic state ('I don't think'). 
This second hypothesis - that daave has speaker-oriented semantics - may help explain why daave is absent in RCs; see $\$ 4.4$.

4.2. STAGE 2: NEG2 IS REANALYZED. As daave's use as a tag increases, the intonational boundary that separates it from the main clause becomes less salient, especially in fast speech. Speakers begin to face the compositionality puzzle mentioned in $\S 1$ : 'How do I analyze the two NEGs in an apparently monoclausal utterance like (34), knowing that the intended meaning has only one semantic negation 's/he didn't see (it)'?

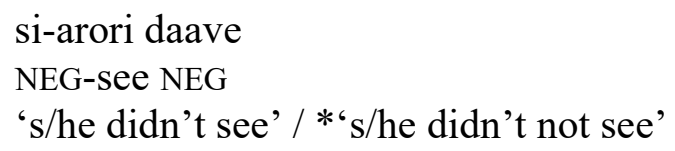

This compositionality puzzle can be solved by treating only one of these NEGs as true semantic negation, and the other as some kind of dependent element - a negative-polarity item (NPI) or negative-concord item (NCI or 'n-word'). In Zeijlstra 2004 terms, this means analyzing one $\mathrm{NEG}$ - either si- or daave - as $i \mathrm{Neg}$, and the other as $u \mathrm{Neg}$. The question is which is which.

One of the defining properties of NPIs and NCIs is that they must be licensed by being in a particular structural position vis à vis the $i \mathrm{Neg}$ operator-e.g., $u \mathrm{Neg}$ must be c-commanded by its licensing $i \mathrm{Neg}$ (Zeijlstra 2004, 2008). Now, because Logoori daave is clause-final, it is structurally ambiguous: it could attach higher (at CP, where it would c-command $s i$-) or lower (at vP or ApplP, where it would be c-commanded by si-). This ambiguity - enabling both of the analyses in Figure 1 - sets the stage for grammar competition.

(i) 'Low daave' structure: daave attaches at $\mathrm{vP} / \mathrm{ApplP}$ ) and is analyzed as NPI/NCI licensed by NEG1 si-/ta- (which retains neg. semantics).
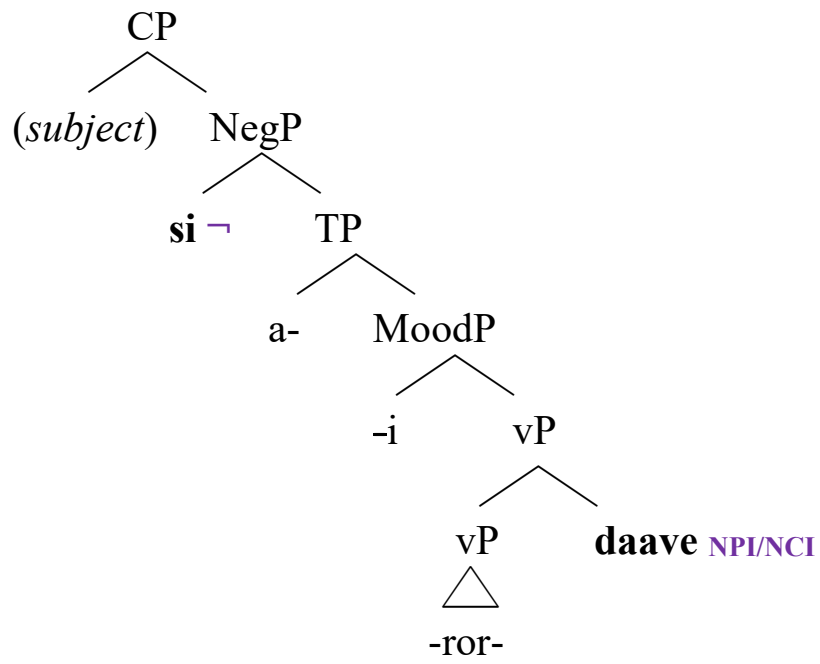

(ii) 'High daave' structure: daave attaches at $\mathrm{CP}$ and retains its negative semantics; $s i$ - is analyzed as NPI/NCI.

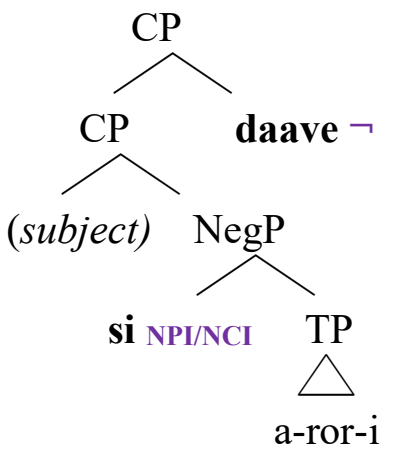

Figure 1. Two possible analyses of si-arori daave 's/he didn't see'

For comparison, the development of 'low daave' in (i) is similar to the path that may have been taken by nohow in some English varieties:
a. [He wouldn't do it], [nohow].
(clause-external tag, semantically NEG)
b. [He wouldn't do it nohow ${ }_{\mathrm{NCI}}$ ]
(vP-level NCI licensed by $n$ 't) 
The development of 'high daave' (ii), on the other hand, is more like the path of English no way, in that no way was originally used in biclausal structures (36)a and is now also used as a clauseinternal (but still clause-peripheral), semantically-negative adverbial (36)b:
a. [There's no way [cP he would do that]]
(CP-selecting head, semantically NEG)
b. [ср No way would he do that]
(CP-specifier, still semantically NEG)

The 'high daave' analysis in (ii) is not available in every type of clause. Subjunctives, in particular, have been argued to have a modal operator in C or Mood that needs to scope over NEG to yield the correct interpretation (37) (see Han 2001). The 'low daave' analysis in (i) is thus the only structure available for Logoori subjunctives.
a. $\checkmark \quad$ it is desired that $\neg p$
MOOD $>$ NEG
[ $\mathrm{C}_{\text {subj }}[$ ta- $[\mathrm{vP} \ldots$ daave $]]$
b. $\mathrm{X} \neg$ it is desired that $p$
$\mathrm{NEG}>\mathrm{MOOD}$
$*\left[\left[\mathrm{C}_{\text {subs }}[\right.\right.$ ta- $[\mathrm{vP} \ldots]]$ daave $]$

In other words, while main-clause indicatives are structurally ambiguous, subjunctives are not. This means that all speakers at stage 2 need to have low daave (Figure 1, i) to analyze negative subjunctives, but not all speakers necessarily have high daave as well (Figure 1, ii).

4.3. STAGE 3: GRAMMAR COMPETITION. Logoori speakers who have high daave (Figure 1, ii) can now begin to produce novel structures without si-, like (38). Such structures may in fact be preferable, since they avoid building a semantically vacuous NegP.

$$
\text { [ст [тр a-ror-i ] daave] 'S/he didn't see (it)' }
$$

Once some speakers begin to produce sentences like (38), other speakers (who may not have hypothesized 'high daave' yet) will have to find a way to parse sentences like (38). One way is to hypothesize high daave. Another is to stick with the low-daave analysis (Figure 1, i) but postulate a null allomorph of Neg, which would variably be inserted instead of si- (see Zeijlstra 2004, 2008 for phonologically-null NC-licensors):

$$
\text { Neg } \leftrightarrow\{\text { si, } \varnothing\} \quad \text { possible PFs: }\{\text { si-a-ror-i daave, Ø-a-ror-i daave }\}
$$

Either way, once everyone has a way to parse sentences like arori daave, they will also be able to produce sentences like arori daave - thus perpetuating a shift to si-less structures.

Negative subjunctives, again, are not structurally ambiguous; they can only be analyzed as in (37)a. It is therefore unsurprising that $t a$ - remains stable; $t a$ - never has to compete with $\varnothing$ as $s i$ - does.

This account allows us to answer the first two questions from the beginning of $\S 4$ : the structural ambiguity of daave leads to grammar competition, which drives the rapid erosion of $s i$ in main-clause indicatives [Q1] without affecting $t a$ - in subjunctives [Q2].

4.4. WhAT ABOUT RELATIVE CLAUSES? I have not yet explained why daave is absent from RCs [Q3]. My provisional hypothesis, as suggested at the end of $\S 4.1$, is that daave is incompatible with RCs (and some wh-questions and conditionals) because it is a speaker-oriented adverb.

Speaker-oriented adverbs are a heterogeneous class including discourse-related adverbs (frankly, briefly), evaluative adverbs (luckily, surprisingly), and modal and epistemic adverbs (probably, clearly) (Ernst 2009, Morzycki 2014). They have several distributional restrictions that are of particular interest here. First, discourse-related and evaluative adverbs tend to be restricted to root or root-like clauses - for example, seriously cannot be interpreted as a speakeroriented adverb in the RC in (40)b, and luckily is odd in the conditional antecedent in (41)b: 
a. John seriously bought a Porsche.

(seriously describes speaker's attitude (surprise) OR John's buying (careful))

b. The car [that John ('seriously) bought] cost him a year's salary. (seriously can only describe John's buying)

(41) a. She has luckily been offered the job.

b. If she has (*luckily) been offered the job, I will be very happy. (Ernst 2009)

On the other hand, these adverbs are fine in root-like clauses, including indirect-discourse embedded clauses (Emonds 2004) and echoic conditionals (Danckaert \& Haegeman 2012):

(42) a. John says that Mary has (seriously / luckily) been offered the job.

b. If she has luckily been offered the job, it must be a better job than I thought it was.

Logoori daave fits this pattern well: it is fine in root clauses and complements of 'say' $((15) b,(20))$, but not in RCs ((24)ff), and is dispreferred in conditionals ((30)-(30)).

Can an adverb be both speaker-oriented and $i \mathrm{Neg} / u \mathrm{Neg}$ ? The English adverbial to my knowledge offers some precedent: to my knowledge refers to the speaker's epistemic state while also showing the distributional restrictions of a strong NPI.

\section{(43) John was *(not) there to my knowledge.}

I hypothesize, then, that Logoori daave has a speaker-oriented semantics independent of and in addition to its $i \mathrm{Neg} / u \mathrm{Neg}$ feature. In its original tag use (stage 1), daave might have meant 'No, I deny/forbid that'; now, as a clause-internal adverb, daave might denote the (non)existence of the preceding event or proposition in the speaker's belief set (' $x$ is(n't) something I believe').
a. [si-arori], [daave]
$\approx$ 'S/he didn't see it, no (I deny that)',
b. $[\mathrm{si}-[$ arori daave $\mathrm{NPI} / \mathrm{NCI}]]$
$\approx$ 'S/he didn't see it to my knowledge'
c. [[arori] daave]
$\approx$ 'Not-to-my-knowledge did s/he see it.'

Note that daave is not necessarily intensifying or 'emphatic.' As such, it is compatible with virtually any negative root or root-like clause. This versatility is what would have enabled speakers to reanalyze daave as the 'main' sentential negator ( $i$ Neg high daave (Figure $1, \mathrm{ii}))$ in the shift from stage 1 to stage 2 above. See $\S 5$ for more discussion.

Of course, it remains to be explained exactly why speaker-oriented adverbs are barred from RCs. See Danckaert \& Haegeman 2012, Ernst 2009, Heycock 2006 for discussion. One possibility is that this is an intervention effect; e.g. speaker-oriented adverbs intervene in an operator chain. Alternatively, there may be something semantically odd about referring to the speaker's belief set in a RC, since RCs are typically used to package given/old information. This latter approach might explain why daave is permitted in the RCs in Kanyoro 1983 (31). It also leads us to expect that speaker-oriented adverbs will be okay in RCs that package new information - a prediction that is borne out in English (45) and remains to be tested in Logoori.

(45) This is a car [that I would (seriously) spend a year's salary on]. $\quad c f$. (40)b

5. Microvariation in Luyia negation. In the analysis just presented, the skewed distribution of Logoori NEG morphemes (Table 1) is attributed to specific features of daave-viz. its clause-final syntax and its speaker-oriented semantics. The implication is that the JC, once underway, manifests very differently from one language to another depending on language-specific factors.

Support for this general approach comes from Logoori's closest (Luyia) relatives. At first sight, negation looks very similar across Luyia — each language has bipartite negation consisting 
of a prefixal cognate of si-/ta- and a clause-final cognate of daave (Kanyoro 1983:96ff). But recent work (Bell 2004, Diercks \& Liu in prep., Diercks et al. 2019) shows that these languages are following very different paths through the JC.

In Wanga and Bukusu, for example, NEG1 is obligatory across all clause types - unlike Logoori, where NEG1 si- is disappearing:

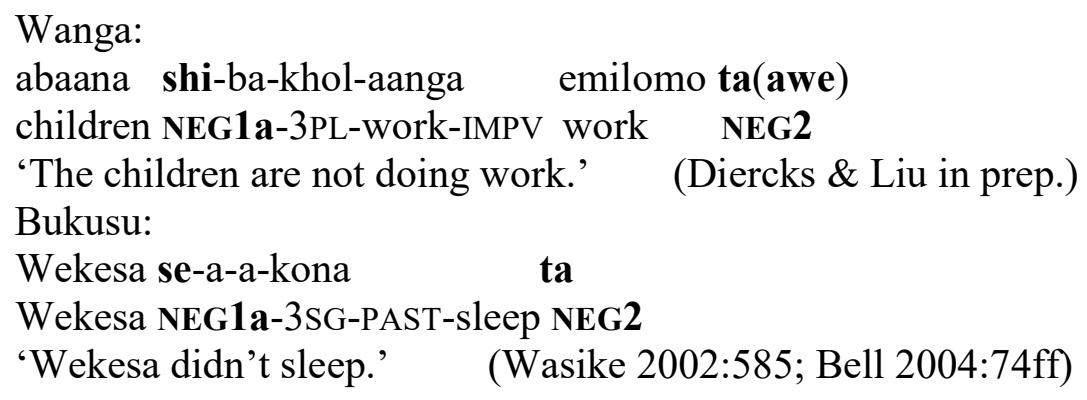

Furthermore, Wanga and Bukusu allow_in fact require-NEG2 in RCs (again unlike Logoori):

(48) Wanga:

amapwoni [aka abaliimi ba-la-acheesere ta]

potatoes REL farmers 2PL-NEG1b-harvest NEG2

'the potatoes that the farmers didn't harvest' (Diercks \& Liu in prep.)

(49) Bukusu:

eenju [niyo Wafula a-a-kho-ombakha ta]

house REL Wafula 3SG-TMA-NEG1b-build NEG2

'a house which Wafula didn't build' (Wasike 2002:585)

Why do NEG1 and NEG2 pattern so differently in these closely related languages?

In $\S 3$ I argued that Logoori daave starts off as a negative tag ('no') and gets reanalyzed by some speakers as a high-adjoining sentential NEG (Figure 1, ii). Importantly, in order for this to happen, daave needs to be frequent enough in discourse to be a plausible sentential negator. (If daave were used in only a small subset of negative sentences, speakers wouldn't entertain the hypothesis that it could be sentential NEG itself.) The speaker-oriented semantics that I posit in $\S 4.4$ - where tag daave means something like 'I say no; I deny' — is indeed compatible with a wide range of negative utterances.

Suppose that in Wanga and Bukusu, the dawe tag borrowed from Luo started out with a slightly different semantics: emphatic 'no, not at all.' In this case, dawe would be restricted to utterances where emphatic negation is intended. The possibility of reanalyzing dawe as a highattaching $i \mathrm{Neg}$ (cf. Figure 1-ii) then never arises; dawe is too infrequent to be a plausible sentential negator at this stage. Consequently, there is no grammar competition and NEG1 shi-/seremains stable. Dawe is instead analyzed as a low-attaching NPI/NCI (Figure 1, i), compatible with RCs and subjunctives as well as main clauses. Over time, through gradual bleaching, it loses its emphatic semantics and starts showing up in all negated clauses.

Could Logoori daave likewise lose its speaker-oriented semantics? Yes, and in this case it would be able to be used freely in RCs, wh-questions and conditionals. But it would not necessarily then become obligatory. Recall that RCs already have $i \mathrm{Neg} t a$ - doing the work of negation. It is not clear, then, why speakers would bother to add a semantically bleached daave to a RC with ta-; daave would not be making any semantic contribution. We might even see 'JC reversal' effects in this scenario - e.g. subjunctives going from ta...daave (JC stage 3) back to taonly (JC stage 1). This kind of reversal would not be unprecedented; see e.g. Biberauer 2009. 
On the other hand, the semantic bleaching of daave could coincide with a simplification of daave's NEG features, so that daave becomes uniformly $i$ Neg whether it attaches high or low. Under this scenario, $t a$ - would become redundant and the JC might advance to stages 4 and 5 in subjunctives and RCs - a shift that may already be underway for some speakers (see (23), (31)) .

The fact that both of these outcomes are imaginable serves to reinforce the take-home message of this paper: that once a JC is underway, it is driven by language-specific forces that lead to variation in the distribution, pace, and even direction of the shift; i.e., there is no single path through the JC.

6. Wrap-up. I have proposed an analysis of negation in Logoori (Bantu, Luyia), where Jespersen-cycle effects vary by clause type (Table 2). I argued that the innovative clause-final particle daave is ambiguous (for at least some speakers) between a CP-level adverb that carries its own semantic negation and a lower-adjoining NCI/NPI licensed by Neg si-or ta-, and that grammar competition drives a rapid shift to JC stage 5 in main clauses. I showed that JC effects take a very different form in Logoori's close relatives Wanga and Bukusu, calling for an analysis involving gradual semantic bleaching rather than grammar competition. The implication is that the Jespersen cycle can be driven by very different forces even in closely related languages underscoring the point that there is more than one kind of Jespersen cycle (Biberauer 2009, van der Auwere 2009).

\section{References}

Appleby, L. L. 1947. A first Luyia grammar with exercises. East African Literature Bureau.

Bell, Arthur J. 2004. Bipartite negation and the fine structure of the negative phrase. Ithaca, NY: Cornell University dissertation.

Biberauer, Theresa. 2009. Jespersen off course? The case of contemporary Afrikaans negation. In Elly van Gelderen (ed.), Cyclical change. 12-58. Amsterdam: John Benjamins.

Danckaert, Lieven \& Liliane Haegeman. 2012. Conditional clauses, main-clause phenomena and the syntax of polarity emphasis. In Peter Ackema et al. (eds.), Comparative Germanic syntax: The state of the art. 133-168. Amsterdam: John Benjamins.

Devos, Maud \& Johan van der Auwera. 2013. Jerspersen cycles in Bantu: Double and triple negation. Journal of African Languages \& Linguistics 34(2). 275-299.

Diercks, Michael \& Kang Liu. In prep. Wanga negation. Manuscript, Pomona College.

Diercks, Michael, Michael Marlo \& Thanh Nguyen. 2019. Tiriki negation. To appear in Michael Diercks \& Michael Marlo (eds.), A grammatical sketch of Tiriki. Berlin: Language Science Press.

Emonds, Joseph. 2004. Unspecified categories as the key to root constructions. In David Adger et al. (ed.), Peripheries: Syntactic edges and their effects. 75-120. Dordrecht: Kluwer.

Ernst, Thomas. 2009. Speaker-oriented adverbs. Natural Language \& Linguistic Theory 27. 497-544. https://doi.org/10.1007/s11049-009-9069-1 .

Gibson, Hanna \& Vera Wilhelmsen. 2015. Cycles of negation in Rangi and Mbugwe. Africana Linguistica, 21. 233-257.

Gluckman, John \& Margit Bowler. 2016. Expletive agreement, evidentiality, and modality in Logooli. Semantics and Linguistic Theory (SALT) 26. 1063-1082. https://doi.org/10.3765/ salt.v26i0.3935.

Han, Chung-hye. 2001. Force, negation and imperatives. The Linguistic Review 18. 289-325.

Heycock, Caroline. 2006. Embedded root phenomena. In Martin Everaert \& Henk van Riemsdijk (eds.), Blackwell companion to syntax. Wiley. 
Jespersen, Otto. 1917. Negation in English and other languages. Copenhagen: Høst.

Kanyoro, Rachel Msimbi Angogo. 1983. Unity in diversity: A linguistic survey of the Abaluyia of western Kenya. Wien: Inst. für Afrikanistik.

Kitabu Kitakatifu (The Bible in Ragoli). 1951. New York: American Bible Society.

Meeussen, A.E. 1967. Bantu grammatical reconstructions. Africana Linguistica 3. 79-121.

Morzycki, Morcin. 2016. Modification. Cambridge, UK: Cambridge University Press.

Nurse, Derek. 2008. Tense and aspect in Bantu. Oxford: Oxford University Press.

Ngonyani, Deo S. 2013. Surrogate negative imperatives in Bantu languages with postverbal negative particles. Selected Proceedings of the 43rd Annual Conference on African Linguistics. 177-187. Somerville, MA: Cascadilla Proceedings Project.

Odden, David. 2018. Tonal melodies in the Logoori verb. In Diane Brentari \& Jackson L. Lee (eds.), Shaping phonology. 70-95. Chicago: University of Chicago Press.

Pak, Marjorie. 2007. Relative clauses without CPs in Luganda. Proceedings of the $37^{\text {th }}$ Western Conference on Linguistics. 189-201.

Sarvasy, Hannah. 2016. The future in Logoori oral texts. In Doris L. Payne et al. (eds.), Diversity in African languages. 201-219. Berlin: Language Science Press.

Sarvasy, Hannah. 2019. Short, finite and one-sided bridges in Logoori. In Valérie Guérin (ed.), Bridging constructions. 79-98. Berlin: Language Science Press.

Schwenter, Scott A. 2006. Fine-tuning Jespersen's cycle. In Betty J. Birner \& Gregory Ward (eds.), Drawing the boundaries of meaning: Neo-Gricean studies in pragmatics and semantics in honor of Laurence R. Horn. 327-344. Amsterdam: John Benjamins.

Van der Auwera, Johan. 2009. The Jespersen cycles. In Elly van Gelderen (ed.), Cyclical change. 35-72. Amsterdam: John Benjamins.

Wasike, Aggrey Khaoya. 2002. On the lack of true negative imperatives in Lubukusu. Linguistic Analysis 32. 584-614.

Wasike, Aggrey Khaoya. 2007. The left periphery, wh-in-situ, and A-bar movement in Lubukusu and other Bantu languages. Ithaca, NY: Cornell University dissertation.

Zeijlstra, Hedde. 2004. Sentential negation and negative concord. Amsterdam: Universiteit van Amsterdam dissertation.

Zeijlstra, Hedde. 2008. Negative concord is syntactic agreement. Manuscript, Universiteit van Amsterdam. 